\title{
ANALISIS SISTEM INFORMASI PENGELOLAAN DATA TRANSAKSI PEMBELIAN CONSUMER UNTUK MANAJEMEN PEMBELIAN PERUSAHAAN
}

\author{
Dewi S.S Wuisan \\ Program Studi Manajeman Universitas Pelita Harapan Tangerang Indonesia \\ E-mail : dewi.wuisan@uph.edu
}

Submission date: 2020-05-26

Accepted date: 2020-06-09

\begin{abstract}
This study aims to determine and also analyze the information system on purchases, especially purchases of goods made by the customer at PT.ABC will help in the management of corporate purchases. The research method used in this study is qualitative research, which is needed to get a picture of the relationship between the subject and the object under study. Where the subject is PT. ABC, as for the object is the information system of purchasing goods by customers. Data collection used in this study through the process of interviews, observation and literature study. To overcome the problems in this research, an information system design for managing consumer purchase transaction data was made to be built using the PHP programming language and Microsoft Access database. Analysis of the data used is to use user analysis and analysis of the current system. The results achieved in this study are able to simplify and speed up data access by updating the financial section, the purchasing department, and the purchasing manager in this case greatly helps the company in monitoring goods.
\end{abstract}

Keywords: Purchasing, Analysis, Customer, PHP

\begin{abstract}
ABSTRAK
Penelitian ini bertujuan untuk mengetahui dan juga menganalisis sistem informasi pada pembelian khususnya pembelian barang yang dilakukan oleh costumer pada PT.ABC akan membantu dalam manajemen pembelian perusahaan. Metode penelitian yang digunakan pada penelitian ini adalah penelitian kualitatif, yang diperlukan untuk mendapatkan gambaran antara hubungan pada subjek dan objek yang diteliti. Dimana subjeknya adalah PT. ABC, adapun objeknya adalah sistem informasi pembelian barang oleh customer. Pengumpulan data yang digunakan dalam penelitian ini melalui proses wawancara, observasi dan studi pustaka. Untuk mengatasi permasalahan dalam penelitian ini maka dibuatlah suatu perancangan sistem informasi pengelolahan data transaksi pembelian consumer yang akan dibangun dengan menggunakan bahasa pemrograman PHP dan database microsoft acces. Analisis data yang digunakan adalah menggunakan analisis pengguna dan analisis sistem yang berjalan saat ini. Hasil yang dicapai dalam penelitian ini adalah dapat mempermudah dan mempercepat akses data secara update pada bagian keuangan, bagian pembelian, dan manager pembelian dalam hal ini sangat membantu perusahaan dalam memonitor barang.
\end{abstract}

Kata Kunci : Pembelian, Analisis, Customer, PHP

\section{PENDAHULUAN}

Saat ini teknologi berkembang dengan begitu pesat yang telah menghantarkan dunia memasuki era yang baru dimana era lebih cepat dan praktis. Perkembangan teknologi juga membawa perubahan pada berbagai bidang kehidupan saat ini seperti pada perdagangan, pendidikan, kesehatan, pariwisata, perindustrian dan berbagai bidang yang lain. Peran teknologi yang saat ini berkembang pesat yaitu peran teknologi dalam menyelesaikan berbagai permasalahan pada bidang perdagangan. Pada bidang perdagangan, teknologi banyak digunakan untuk mengelola berbagai data atau dokumen transaksi agar menjadi suatu informasi yang lebih berguna sebagai bahan pengambilan keputusan.

Pengolahan data adalah suatu proses menerima dan mengeluarkan data menjadi bentuk lain yaitu berupa informasi. Pengolahan data terdiri dari penyimpanan data (data storage) yaitu penyimpanan data meliputi pekerjaan pengumpulan (filling), pencarian (searching), dan pemeliharaan 
(maintenance). Dan penanganan data (data handling) yaitu penanganan data meliputi berbagai kegiatan, seperti pemeriksaan (verifying), perbandingan (comparing) pemilihan (sorting), peringkasan (extracting), dan penggunaan (manipulating) (Tata Sutabri, 2005).

Dalam Kamus Besar Bahasa Indonesia, transaksi dapat diartikan sebagai persetujuan jual beli didalam perdagangan yang terjadi dua pihak dan dapat diartikan sebagai tindakan pelunasan atau pembayaran (Alwi Hasan, 2005).

Menurut (Azhar Susanto, 2013) transaksi adalah peristiwa aktivitas bisnis yang terjadi didalam suatu perusahaan. Pengertian tunai yang ada di dalam kamus besar bahasa indonesia yaitu tidak bertanggung lagi, tidak bertangguh dalam hal pembayaran yaitu pada saat itu juga atau bersifat kontan.

Transaksi penjualan secara tunai pada barang maupun jasa, kemudian akan diberikan oleh perusahaan untuk pembeli apabila perusahaan telah menerima uang dari pembeli dan keputusan yang dilakukan dalam proses pembelian adalah merupakan tindakan dari pembeli untuk dapat membeli ataupun tidak terhadap suatu produk (Kotler, P., \& Armstrong, 2014).

Sistem merupakan jaringan proses prosedur yang dibuat berdasarkan pada pola yang tersistematis dalam melaksanakan kegiatan penting pada perusahaan. Adapun sistem merupakan kerangka dari prosedur-prosedur yang saling berhubungan secara tersusun menurut suatu skema yang bersifat menyeluruh untuk dapat melaksanakan kegiatan atas fungsi tugas penting dari perusahaan (Mulyadi, 2010).

Berdasarkan definisi-definisi mengenai system tersebut, maka dapat diambil kesimpulan yaitu sistem merupakan sekelompok bagian yang erat yang saling berhubungan satu sama lain untuk dapat melaksanakan proses kegiatan yang dilakukan secara bersama-sama untuk dapat mencapai suatu tujuan.

\section{METODE PENELITIAN}

Metode perancangan yang dilakukan adalah suatu proses yang mendefinisikan sesuatu yang kemudian akan dikerjakan menggunakan teknik yang bervariasi dan didalamnya melibatkan deskripsi berupa arsitektur dan hal detail komponen yang juga meliputi keterbatasan yangterjadi pada saat proses pengerjaannya sehingga dapat dikatakan bahwa perancangan merupakan tahapan analisis sistem dimana tujuannya agar supaya dapat menghasilkan model rancangan yang sesuai kebutuhan yang sudah ditentukan selama proses tahap analisis (Rizky Soetam, 2011).

Tahapan yang terjadi pada perancangan sistem yaitu merancang sistem secara rinci yang didasarkan pada hasil analisis sistem yang ada, sehingga dapat menghasilkan model sistem baru yang baru (Mahdiana, 2011).

Penelitian ini merupakan penelitian kuantitatif yang menggunakan metode reseach action. Penelitian dilakukan pada bagian keuangan dan bagian pembelian PT ABC dengan menggumpulkan data secara primer dan sekunder melalui observasi langsung, wawancara dan dokumentasi ( Budiyantara et al., 2020)

Metode Perancangan dalam merancang sistem, menggunakan diagram dengan notasi UML. Unified Modeling Language (UML) merupakan bahasa standar yang sering digunakan saat menulis blueprint pada perangkat lunak. UML biasa dipergunakan saat menvisualisasikan, menspesifikasikan maupun membangun, dan saat mendokumentasikan artifak dari pada sistem perangkat lunak (Yuni Sugiarti, 2013).

Sedangkan PHP secara umum lebih dikenal sebagai bahasa pemrograman script - script saat membuat dokumen HTML, dokumen HTML yang dihasilkan pada suatu aplikasi bukan merupakan dokumen HTML yang dibuat menggunakan editor teks atau editor HTML (Sidik, 2012).

\section{HASIL DAN PEMBAHASAN}

\section{Rancangan Sistem yang Diusulkan}

Gambar dibawah ini merupakan gambar use case diagram yang diusulkan untuk dapat melihat gambar proses pembelian barang di PT. ABC:

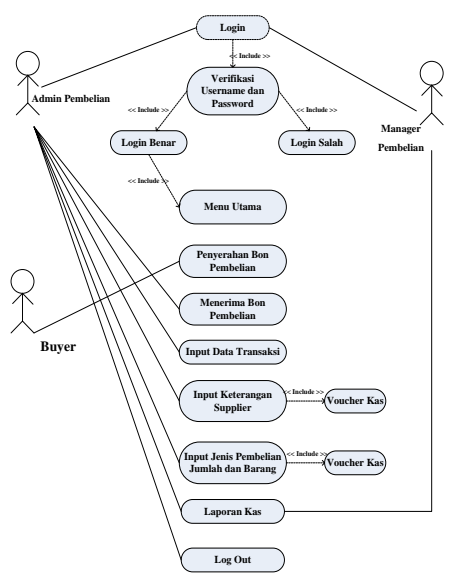

Sumber : (Dewi S.S Wuisan, 2020)

Gambar 1. Use Case Diagram Usulan Pembelian Tunai 
terdapat :

Dari gambar 1 Use Case diagram usulan

a. Sistem yang merupakan seluruh kegiatan sistem pembelian tunai PT. ABC

b. Actor ada 3 yaitu Admin Pembelian, Buyer dan Manager Pembelian.

c. Use Case yang akan dilakukan ketiga aktor tersebut yang diantaranya: Registrasi dalam bentuk login, penyerahan bon tunai, menerima bon pembelian, input data transaksi, input keterangan supplier, input jenis pembelian jumlah dan barang, laporan kas dan log out.

\section{Activity Diagram Usulan}

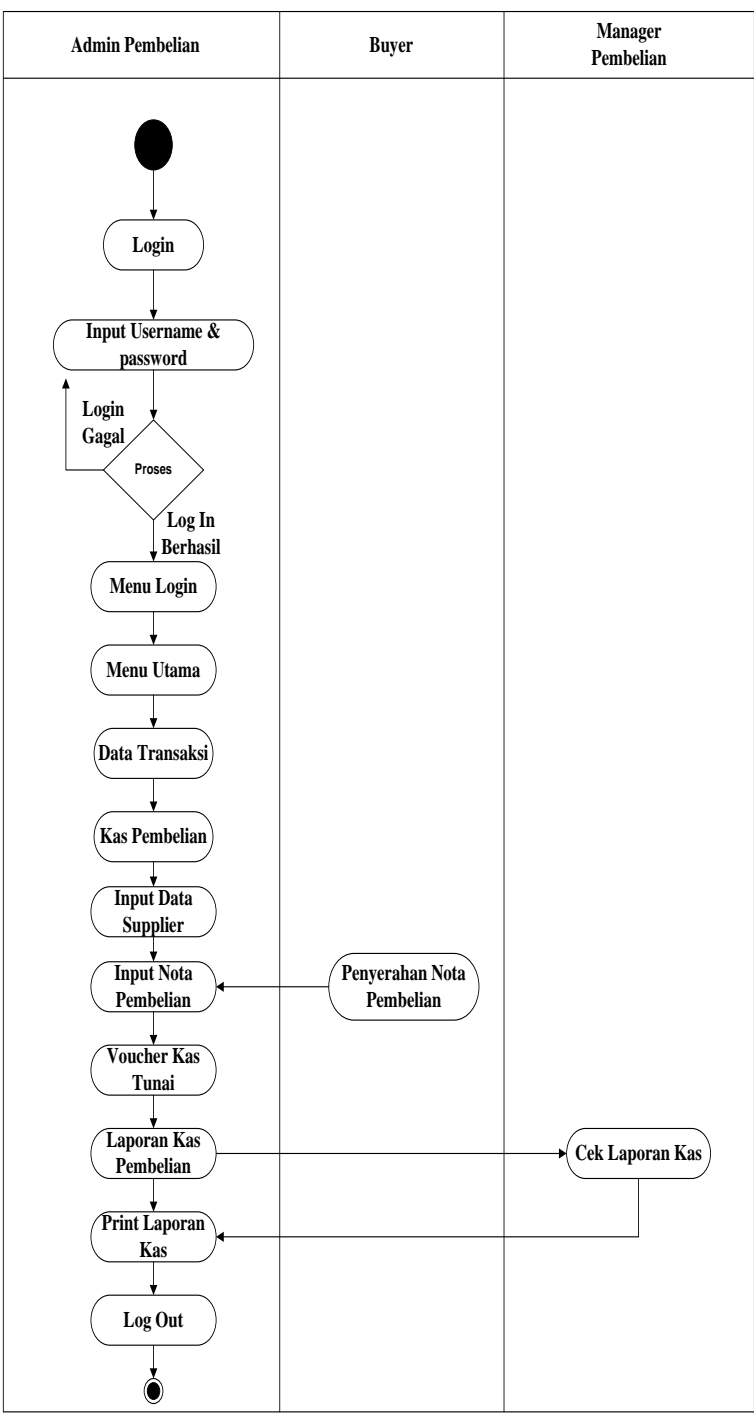

Sumber : (Dewi S.S Wuisan, 2020)

Gambar 2. Activity Diagram Usulan Pembelian Tunai
Berdasarkan gambar 2 Activity diagram yang diusulkan terdapat 1 (satu) initial node dan 1 (satu) final node. Pada rancangan activity diagram yang diusulkan terdapat 14 (empat belas) action dan juga 1 (satu) desicion yang menggambarkan proses validasi untuk pengambilan keputusan dalam proses login. Pada rancangan ada 2 faktor yang dapat mengakses sistem pembelian tunai, yaitu :

Manager peembelian serta Admin Pembelian dapat mengakses login, pembuatan dan pemeriksaan laporan pembelian, dan logout.

\section{Sequence Diagram Usulan}

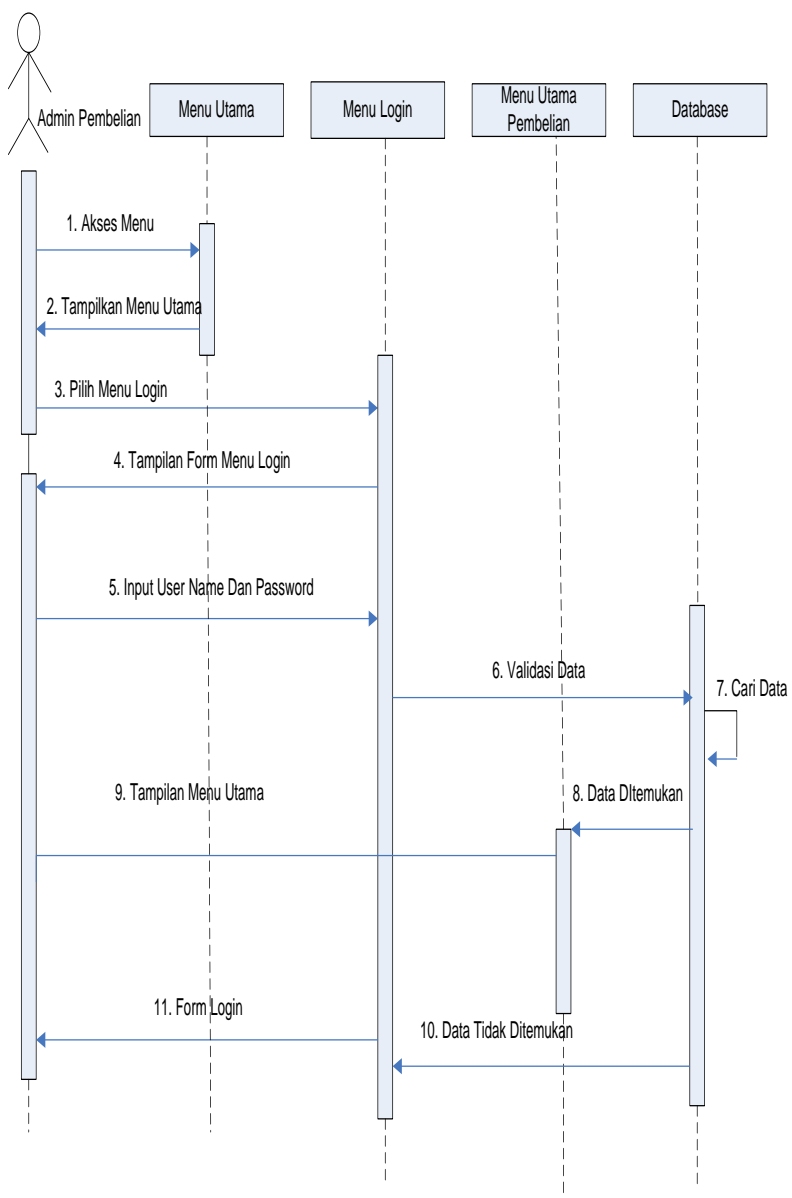

Sumber : (Dewi S.S Wuisan, 2020)

Gambar 3. Sequence Diagram Usulan Pembelian

Rancangan Class Diagram

Class Diagram adalah merupakan spesifikasi yang apabila diinstalasi dapat menghasilkan sebuah objek dimana merupakan inti daripada pengembangan objek dan desain berorientasi objek. 


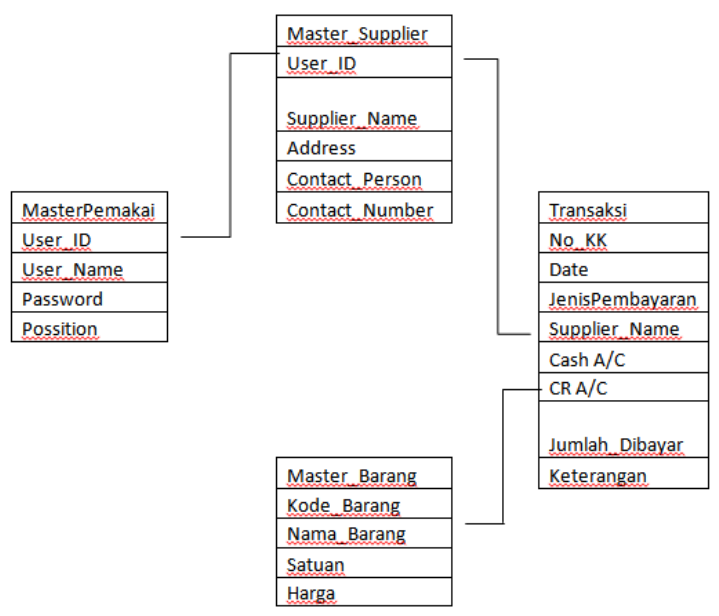

Sumber : (Dewi S.S Wuisan, 2020)

Gambar 4. Rancangan Class Diagram Usulan

\section{Rancangan Dialog Layar}

\section{Menu Login}

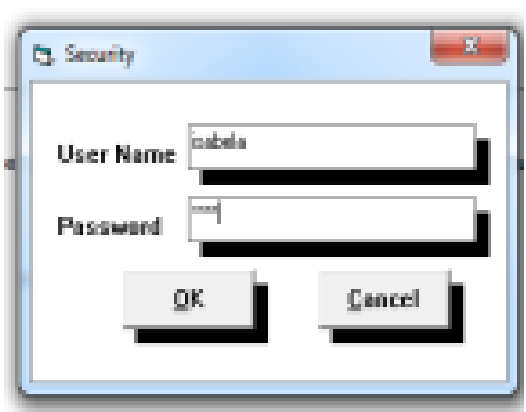

Sumber : (Dewi S.S Wuisan, 2020)

Gambar 5. Tampilan Menu Login

\section{Menu Utama}

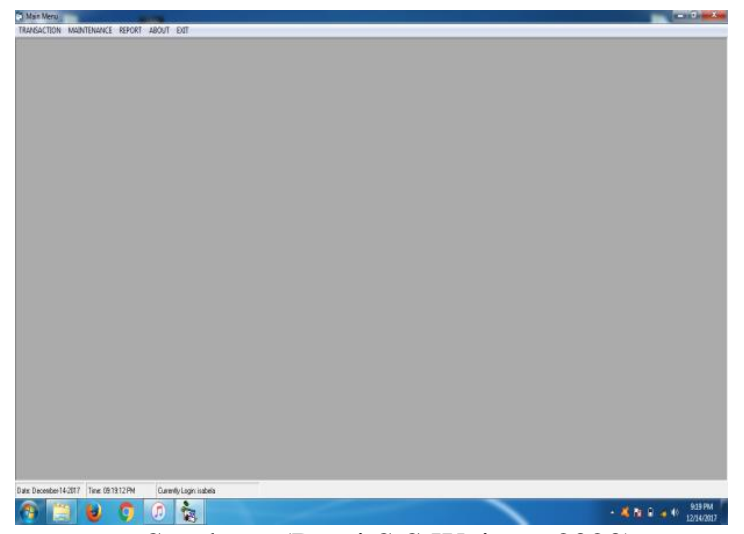

Sumber: (Dewi S.S Wuisan, 2020)

Gambar 6. Tampilan Menu Utama
3. Menu Transaksi (Pembelian)

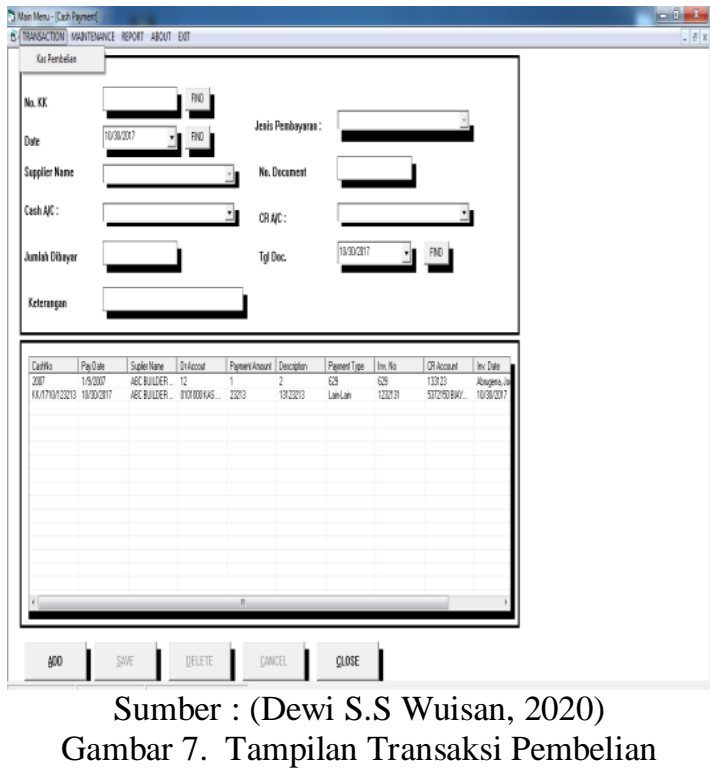

\section{KESIMPULAN}

Dari hasil penelitian ini dan pengamatan yang sudah dilakukan pada PT. ABC, dapat disimpulkan bahwa pengembangan sistem informasi pengelolahan data transaksi yang dilakukan melalui pemodelan sistem berbasis objek yang sudah dilakukan untuk membantu data transaksi pembelian oleh konsumen, dapat mempermudah dan mempercepat bagian keuangan, bagian pembelian dan manager pembelian untuk dapat mengakses data secara update yang nantinya dalam hal ini akan sangat membantu perusahaan dalam memonitor barang yang sudah terjual dan membantu mengelolah manajemen keuangan perusahaan.

\section{DAFTAR PUSTAKA}

Agus Budiyantara, Irwansyah, Egi Prengki, P. A. P. (2020). Komparasi Algoritma Decision Tree, Naive Bayes Dan K-Nearest Neighbor Untuk Memprediksi Mahasiswa Lulus Tepat Waktu.

Alwi Hasan. (2005). Kamus Besar Bahasa Indonesia (3rd ed.). Balai Pustaka.

Azhar Susanto. (2013). Sistem Informasi Akuntansi Struktur Pengendalian Resiko Pengembangan (1st ed.). Lingga Jaya.

Dewi S.S Wuisan. (2020). Analisis Sistem Informasi Pengelolaan Data Transaksi Pembelian Consumer Untuk Manajemen Pembelian Perusahaan. 
Kotler, P., \& Armstrong, G. (2014). Kotler, P., \& Armstrong, G. Pearson Education.

Mahdiana, D. (2011). Analisa Dan Rancangan Sistem Informasi Pengadaan Barang Dengan Metodologi Berorientasi Obyek: Studi Kasus $\mathrm{Pt}$. Liga Indonesia. Jurnal TELEMATIKA MKOM, Vol.3 No.2, September 2011 ISSN 2085-725X, 3(2), 36-43.

Mulyadi. (2010). Sistem Akuntansi (3rd ed.). Salemba Empat.
Rizky Soetam. (2011). Konsep Dasar Rekayasa Perangkat Lunak. Balai Pustaka.

Sidik, B. (2012). Pemrograman Web dengan PHP. Informatika.

Tata Sutabri. (2005). Sistem Informasi Manajemen. Andi.

Yuni Sugiarti. (2013). Analisis dan Perancangan UML (Unified Modeling Language) Generated VB.6. Graha Ilmu. 
